\title{
The correlation between critical thinking and emotional intelligence, conflict management modes in Chinese medical undergraduates: a cross-sectional study
}

\section{Yuan Li}

Jilin University

Kun Li Jilin University

Wenqi Wei

Jilin University

Jianyu Dong

Jilin University

Canfei Wang

Jilin University

\section{Ying Fu}

Jilin University

Jiaxin Li

Jilin University

Xin Peng ( $\square$ pengxin2016@163.com )

Jilin University https://orcid.org/0000-0002-9496-6556

\section{Research article}

Keywords: Critical thinking, Emotional intelligence, Conflict management modes, Medical undergraduates

Posted Date: July 11th, 2019

DOI: https://doi.org/10.21203/rs.2.11234/v1

License: (c) (i) This work is licensed under a Creative Commons Attribution 4.0 International License. Read Full License 


\section{Abstract}

Background Medical students are supposed to utilize critical thinking (CT) to resolve problems in healthcare settings. And the complex clinical environment requires effective collaboration and communication. Students with higher emotional intelligence (EI) are more sensitive and can cope with the interpersonal communication better. Conflict is also inevitable in the medical workplace. This study aimed to evaluate the levels of CT, El and conflict management modes (CMM) of the medical undergraduates, explore the correlation between $\mathrm{CT}$ and El, $\mathrm{CMM}$, and provide a theoretical evidence basis for the medical education. Methods A cross-sectional study of medical students from Jilin University was conducted using a questionnaire containing three parts: Critical Thinking Disposition Inventory-Chinese Version (CTDI-CV), Emotional Intelligence Scale (EIS) and Rahim Organizational Conflict Inventory-II (ROCI-II). Demographic data relating to gender, grade and specialty were also collected. Data was analysed using T-tests, Pearson correlation analysis and multiple regression analysis. Results A total of 282 (95.39\% response rate) medical undergraduates participated in this study. Students had a positive level of CT (Mean (SD) $=281.12(27.40)$ ). There was a positive correlation between the overall CT skills and the overall El competencies $(\mathrm{P}<0.01)$. For each dimension of ROCI-II, the total CTDI-CV score was significantly positively associated with integration and compromise scores $(p<0.01)$, significantly negatively associated with domination and compliance scores $(p<0.01)$ but not with avoidance score. The integration, perceived mood, compliance, dominance, and self-emotional regulation were good predictors of overall CT (adjusted R2 = 0.355). Conclusions Our findings showed medical undergraduates' CT had significant correlations with $\mathrm{El}$ and $\mathrm{CMM}$. In other words, it was possible that the development of El and conflict management skills might improve medical students' $\mathrm{CT}$. Therefore, further study is needed to uncover how educators can effectively foster El and conflict management abilities to enhance the level of CT. The trial registration number (TRN) ChiCTR1800015784 Date of registration 2018/04/20 Keywords Critical thinking, Emotional intelligence, Conflict management modes, Medical undergraduates

\section{Background}

The development of critical thinking skills has long been considered as a priority in higher medical education [1]. CT is described as making purposeful and advisable judgments as a result of engaging in a process of analysis interpretation evaluation inference explanation, and reflection [2]. People who have strong CT skills exhibit keen thoughts, a burning curiosity, and a thirst for reliable information. CT skills are required for an era when biomedical knowledge base is expanding exponentially and acquisition alone is not enough for medical workers to work in current clinical conditions [3]. Medical education should be more about how to handle and apply knowledge using CT abilities in the future, not just to impart it to the students. Individuals compare and make decisions repeatedly with CT skills - comparing existing knowledge with new knowledge and then judging how to act on those comparisons based on analysis mechanism [4,5]. CT skills are indispensable to the development of medical science and technology. Healthcare professionals with strong CT can break through the constraint of the existing information, and generate new medical knowledge and innovations of using old and new knowledge [6].

The courses of clinical decision-making and problem-solving demand CT skills [3]. Health professionals need to effectively cope with complex and demanding clinical situations in fast rhythm environments. Medical workers need advanced CT skill to accomplish actions that directly affect patient results $[7,8]$. These actions include 
analyzing patients' cases, considering patients' emotions and weighing possible therapeutic measures, then recognizing which treatment is the most appropriate [9]. Additionally, CT is increasingly important for medical practitioners to criticize and use evidence [10], because medical professionals must deal with a large number of misinformation on the network and the fact that various aspect of scientific knowledge is full of uncertainty. Hence, a crucial aim of medical education is to develop students' CT skills in preparation for clinical practice [11].

Emotional intelligence (EI) is defined as "the ability to control one's own and others' emotions , to distinguish among them, and to guide one's thinking and action with this information [12]." El skills are crucial important to many parts of individual functioning. Evidences have demonstrated that El has a significant effect on creativity, academic success, human mental health and cognitive-based performance [13-16]. El is an important skill for medical students that should be actively fostered. El works on when medical personnel make decisions during curing period, build rapport with patients, handle medical team collaboration, and deal with workplace pressure [17-20]. Medical students with higher El skills may result in excellent graduates and stronger clinical performance [21, 22]. According to Kaya et al. [23], research on El of nursing students is pivotal because it can affect the quality of their CT skills, adoption of evidence-based practice and practice-based knowledge in their practice. Despite its importance, there is little empirical research on CT and El of medical undergraduates.

Research conducted by Pines et al. [24] confirmed that medical students with effective conflict management skills, were good for preparing them for the challenges of healthcare environment. Health maintenance organizations are complex and require a mass of teams to provide healthcare. Whenever healthcare providers work together as a team, conflict can emerge in these environments - some would deem to be necessary [25]. The method to promote teamwork is not to avoid but to effectively manage intergroup and intragroup disagreement, incompatibility, or other conflicts [26]. All conflict is not problematic and when effectively managed conflict can have positive effects on results and fostering coordination, collaboration, and professional productivity; unfortunately, poor conflict management modes (CMM) can be costly. Studies found that ineffective CMM on hospital units can undermine job satisfaction, group dynamics, and patient outcomes [27-29]. According to Browne et al. [30], individuals with strong CT bring to conflict conditions skills that create a win-win conflict solution. Little empirical study, however, has looked at how CT skills are related to CMM in medical students.

Previous study has proved the correlation between CT and El as well as that between CT and CMM, but little research, to the best of our knowledge, has looked at these in medical undergraduates. Therefore, our study served two purposes. First, the study aimed to explore the levels of CT, El and CMM of medical undergraduates. Second, our study also aimed to assess whether the relationship existed between CT and El, CMM.

\section{Methods}

\section{Study design}

A cross-sectional, anonymous study was undertaken with medical undergraduates in Jilin University. The study was approved by Jilin University Human Ethics Committee (Approval No. 2018041601). 


\section{Participants}

Participants were recruited from a stratified random sample of medical undergraduate students in Jilin University. Participation was innominate and voluntary. 269 students (95.39\% of invited students) took part in the study. The Raosoft sample size calculator [31] was used to obtain a suitable sample size based on the study setting's overall medical undergraduates $(\mathrm{N}=2987)$. This process resulted in a recommended sample size of 249 , which gave a $90 \%$ confidence level with a $5 \%$ margin of error. Characteristics of the participants are summarized in Table 1.

\section{Data collection}

Data collection was conducted between August to October, 2016. Prior to data collection, the researchers offered all participants with sufficient disclosure of their rights, the purpose, benefits and risks of the study. The questionnaire included socio-demographic questions (gender, grade, major, average grade reading habits, parttime experience and internship experience) and three reliable and valid scales used previously in the literature to measure $\mathrm{CT}$, El and CMM.

\section{Critical thinking assessment}

Critical Thinking Disposition Inventory-Chinese Version (CTDI-CV) was used to measure medical students' CT disposition. This questionnaire was modified by Peng [32] according to Facione 's California Critical Thinking Dispositions Inventory [33]. The scale has 70 items in seven sub-scales: truth-seeking, open-mindedness, analyticity, systematicity, CT self-confidence, inquisitiveness and cognitive maturity. Respondents were asked to rank their agreement with each comment on a 6-point scale from 1 (absolutely do not agree) to 6 (absolutely agree). Alpha reliabilities for the seven subscales in the initial sample ranged from 0.54 to 0.77 , and the alpha reliability for the overall CT dispositions was 0.90 , demonstrating good reliability. Total scores had a possible range for total CTDI-CV scores is from 70 to 420 , with higher score indicating stronger CT ability. During analysis of CT, a score over 350 were considered to indicate a strong positive CT propensity; a score range from 280-349 presented a positive disposition of CT; a score range from 210-279 were defined as an unclear tendency of CT; and scores below 210 indicated a negative CT disposition.

\section{Emotional intelligence scale}

Emotional Intelligence Scale (EIS) is a 33-item scale designed to measure an individual's El. The questionnaire, revised by Professor Wang [34], has good reliability and validity. The EIS measures four El variables. The four areas or branches of El include perceived emotion, self-emotional regulation, regulation of others emotions and use of emotions. The scale uses a five-point Likert response scale, ranging from 1 (completely non-compliance) to 5 (completely suitable). The highest score possible on composite is 165 and the lowest is 33 . During analysis 
of El, scores above 73 are considered high, scores between 50 and 73 are considered normal, and scores below 50 are considered low.

\section{Rahim conflict management assessment tool}

Rahim Organizational Conflict Inventory-II (ROCI-II), revised by Zhang [35], has 24 items to measure the five subscales of CMM which are integration (7 items), domination (4 items), avoidance (5 items), compliance (5 items) and compromise ( 3 items). Cronbach's alpha was found to be 0.78 [35]. This scale is scored on a 5-point Likert-type scale of 1 to 5 ( 1 = strongly do not agree to $5=$ strongly agree). The higher the score of each independent type manifests more agreement with that particular CMM.

\section{Statistical analysis}

All data were analyzed using SPSS Version 21.0. Significance level was set at 0.05 using a two-tailed test; therefore any $\mathrm{p}$-values smaller than 0.05 indicated a statistically significant association. Demographic characteristics of participants were performed using descriptive statistics. Means and standard deviations were reported for $\mathrm{CT}$, El and $\mathrm{CMM}$ scores. A t-test was used to identify whether there was a significant change in mean total El with sex (testing whether the difference in gender was statistically different from zero). Pearson correlation analysis was performed to examine the association between CT, EI and CMM. To identify predictors of CT, multivariate stepwise linear regression analysis was conducted for the total EIS score, and the EIS and ROCI-II subscales scores.

\section{Results}

\section{Level of CTaEl and CMM}

The average total CTDI-CV score was $281.12 \pm 27.40$ (range = 219-370), indicating a positive CT disposition among the participants. However, only 4 (1.49\%) students' scores were above 350 and a strong CT disposition. None (0\%) scored less than 210 , presenting a negative disposition of CT. The factor scores of CT were ranked as inquisitiveness, analyticity, cognitive maturity, open-mindedness, self-confidence, systematicity and truth-seeking (Table 2).

The mean EIS was $123.03 \pm 15.13$ (range 58-155), indicating that the medical students' El was high. Table 3 presents the distribution of El in male and female survey participants. There were significant differences of EIS and each subscale in gender, where the female students appeared to score higher than the male students (all pvalues< 0.05).

Table 4 details the dimension scores of CMM were ranked as integration, compromise, avoidance, compliance, dominance. 


\section{Association between $\mathrm{CT}$ and EI, CMM}

Except the correlation between truth-seeking and use of emotions for the whole participants non-significant $(r=$ $0.116)$, the various dimensions of CTDI-CV and EIS were a significant positive correlation $(p<0.01)$. Scores on all the ROCI-II module assessments were compared to the CTDI-CV scores using Pearson's correlation coefficient. Medical undergraduates' mean CTDI-CV was significantly positively associated with integration and compromise scores $(p<0.01)$, significantly negatively associated with domination and compliance scores $(p<$ 0.01 ) but not with avoidance score (Table 5).

Because El and CMM have an impact on the medical undergraduates' CT, we conducted multiple regression analyses on the EIS and ROCI-II subscales, and the total CTDI-CV results. Higher levels of perceived emotion and self-emotional regulation, and the more tending to apply integration, compliance and domination styles were significant predictors of stronger CT skills, with the model for total CTDI-CV score $\left(R^{2}=0.364\right.$, adjusted $R^{2}=$ $0.355, p<0.01$ ) accounting for $35.5 \%$ of the variance in total CTDI-CV scores (Table 6). According to the table, the dependent variable regression equation can be written as follows: $\mathrm{CT}$ regression $=0.31$ integration + 0.199 perceived emotion -0.218 compliance -0.138 domination +0.159 self-emotional regulation.

\section{Discussion}

We sought to explore levels of $\mathrm{CT}$, El and CMM in medical undergraduates and this study is the first to assess the relationship between $\mathrm{CT}$ and El, CMM in medical students in China. The results from our study suggest medical educators that they should take the characteristics of the students in to account, especially how El and CMM can contribute to the capacity to foster CT skills. Furthermore, medical educators need to be conscious of how CT can be improved.

\section{The status of CT}

The CT mean score was 281.12, which was higher than the established standards by Facione [33]. Our findings suggest that medical undergraduates showed a positive overall disposition to think critical. This result resembles the previous research conducted by Huang [36] and Raymond [37]. Students met or exceeded the 40point cut on the open-mindedness, analyticity, inquisitiveness, and cognitive maturity subscales. Similar to other studies, inquisitiveness was found to score the highest $[7,36]$. High scores for inquisitiveness indicated a greater potential for the improvement of CT and clinical practice capabilities. CT skills are important for health professionals, as they need to meticulously analyse and solve problems - making good use of inquisitiveness and questioning of information and decisions.

The findings indicated that students showed the weakest performance on the subscale of truth-seeking. In other words, students were lack of honest and objective attitude about pursuing for truth or to reconsider decisions based on new evidence. Disappointing as this may be, the subscale of truth-seeking score in fact is consistent with that in other studies with healthcare students $[11,36]$. This suggested a potential area for the focus of courses that could facilitate the likelihood of medical students using their truth-seeking skills. Traditional 
medical education has been largely restricted to memorizing diseases knowledge. Traditional didactic course passively delivers information and relies solely on lectures, and does not require students active participation to reflect on the meanings being 'delivered', hence limiting the development on scores in the truth-seeking subscale. Hence, further strengthening truth-seeking characteristic in the medical education may be advantageous. This characteristic can provide patients with more responsible medical services.

\section{The correlation between CT and El, CMM}

A statistically significant difference was observed between students' gender and El. The difference was attributed to female students as their El was higher than male students' at a significant level. The study conducted by Czabanowska et al. yielded similar result [38]. Mostly the females are more sensitive and generally more concerned about other people's emotion as compared with males. Our study showed a positive correlation between CT and El. Except the correlation between truth-seeking and use of emotions for the medical students statistically non-significant, the various subscales of CTDI-CV and EIS were a significant positive correlation. We found the perceived emotion and self-emotional regulation were the predictors of CT skills. Therefore, it is likely that medical students' El plays an important role in the regulation of CT skills, and that good critical thinkers are more effective in handling emotions when face with ambiguity [23]. Higher El is associated with increased cognitive competence, more rational behavior, and improved sociability [15]. The students with higher El are more flexible and more tolerant when confront with academic pressure, social anxiety, and complex clinical conflicts [39]. Our findings indicated that medical educational professionals prepared specifically for the improvement of CT or El can help to foster both abilities positively.

Undergraduate medical students in this study preferred to use integrating style to manage conflict. This result is similar to the previous study conducted by Chan [40]. Integrating style which is the most effective in CMM may be the preferred CMM within the medical students. The total CT shows the conspicuous positive correlation with integration and compromise styles, significant negative correlation with domination and compliance subscales, but not with avoidance. Furthermore, integration, compliance and domination dispositions were significant predictors of CT. This result could manifest the significant presence of CMM effect on CT skills in medical education. Relationship conflicts are inevitable in the clinical work and cost a lot, including stress, burnout, medical error, and turnover. Complete elimination of workplace conflict is unrealistic [41]. Dealing effectively with conflict is a crucial capability for teamwork and the provision of patient service. That may contribute to cultivating medical students for the various challenges of healthcare setting [24]. The complex clinical environment requires effective collaboration, communication, decision thinking, and competencies to handle conflicts. Critical thinkers bring to conflict situations abilities that promote win-win conflict resolution [30]. The strong positive correlation between CT and CMM may imply that our study provide a good foundation for further development of CT skills in the future.

The linear regression showed that perceived emotion, self-emotional regulation, integration, compliance and domination styles were significant predictors of CT. Therefore, El and CMM can contribute to the capacity to foster CT skills. Students with stronger CT have better clinical performance and higher academic achievement [42]. Medical educators can provide students with platform to work in teams. In the team, students can learn to 
manage emotions, deal with relationship and task conflicts, and learn to think critically. The application of situational teaching can also foster the development of medical students' CT, El and conflict management skills.

\section{Limitations}

Our study need to be considered in light of the following limitations. Firstly, a large proportion of our respondents were from the same university and not across China. Although this may cast a gloom over other results, given the homogeneity in responses and accordance with previous studies we think this does not deny our capacity for deducing meaningful findings. In addition, self-reported questionnaires, such as the CTDI-CV only measures the CT disposition not the application of these abilities in practice. As such, self-reported tools may be influenced by social desirability, and the ability of students to accurately self-reflect on their own skills. This could have influenced the results to our survey. However, all the scales used in this study have been shown to produce acceptable results and as such are appropriate for assessing CT, El and CMM. Finally, because the study was cross-sectional in nature, correlations between $\mathrm{CT}$ and El, CMM may be the result of the overall correlations, rather than the passage of time. Nevertheless, all the participants in this study were similar in age and educational background, lending credence to the findings of this research.

\section{Conclusions}

CT is important for the quality of patient service, and the scientific development of healthcare. Our study makes an important contribution to the process of improving medical students' comprehensive ability by showing correlation between $\mathrm{CT}$ and $\mathrm{El}, \mathrm{CMM}$. Medical undergraduates who were more positive $\mathrm{CT}$ disposition performed better in El, and preferred to take integrate style. Critical thinking can help medical students better adapt to changing clinical settings. Equipping medical students with more mature El and conflict management skills may ultimately lead to stronger CT capacities and superior graduates as they enter the healthcare environment. Medical educatorsmprove students' teamwork ability so that they can learn to use CT skills to grasp emotions and handle conflicts in a team.

\section{Abbreviations}

CT: Critical thinking; El: Emotional intelligence; CMM: Conflict management modes; CTDI-CV: Critical Thinking Disposition Inventory-Chinese Version; EIS: Emotional Intelligence Sale; Rahim Organizational Conflict InventoryII: ROCI-II

\section{Declarations}

\section{Acknowledgements}

We would like to thank all students from the Jilin universities for participating in this study.

\section{Funding}


This study was supported by the Research Fund of Jilin University (Project No: 2016B74797). The funders had no influence on the design of the study, data collection, analysis and interpretation, or writing of the manuscript.

\section{Availability of data and materials}

The datasets used and/or analyzed during the current study are available from the corresponding author on reasonable request.

\section{Authors' contributions}

LY, LK, PX designed this study, interpreted the data, statistical analyses, and drafted the manuscript. WWQ, DJY, WCF, FY, LJX performed data collection, interpretation, and helped to draft the manuscript. LY and LK drafted the manuscript contributing equally to that task. All authors read and approved the final manuscript.

\section{Ethics approval and consent to participate}

Ethical approval was given by the education department of Jilin University School of Nursing Ethics Committee (File No. 2018041601). Consent was considered obtained if the participant filled out the survey.

\section{Consent for publication}

Not applicable.

\section{Competing interests}

The authors declare that they have no competing interests.

\section{References}

1. Lee J, Lee Y, Gong S, Bae J, Choi M. A meta-analysis of the effects of non-traditional teaching methods on the critical thinking abilities of nursing students. BMC Med Educ. 2016;16:240.

2. Halpern DF. Teaching critical thinking for transfer across domains - Dispositions, skills, structure training, and metacognitive monitoring. Am Psychol. 1998;53(4):449-55.

3. Papp KK, Huang GC, Clabo LML, Delva D, Fischer M, Konopasek L, Schwartzstein RM, Gusic M. Milestones of Critical Thinking: A Developmental Model for Medicine and Nursing. Acad Med. 2014;89(5):715-20. 
4. Holmes NG, Wieman CE, Bonn DA. Teaching critical thinking. Proc Natl Acad Sci U S A. 2015;112(36):11199-204.

5. Eggers F, Lovelace KJ, Kraft F. Fostering creativity through critical thinking: The case of business start-up simulations. Creat Innov Manag. 2017;26(3):266-76.

6. Morrall P, Goodman B. Critical thinking, nurse education and universities: Some thoughts on current issues and implications for nursing practice. Nurse Educ Today. 2013;33(9):935-7.

7. Pu D, Ni J, Song D, Zhang W, Wang Y, Wu L, Wang X, Wang Y. Influence of critical thinking disposition on the learning efficiency of problem-based learning in undergraduate medical students. BMC Med Educ. 2019;19:1.

8. Zuriguel Perez E, Lluch Canut MT, Falco Pegueroles A, Puig Llobet M, Moreno Arroyo C, Roldan Merino J. Critical thinking in nursing: Scoping review of the literature. Int J Nurs Pract. 2015;21(6):820-30.

9. Li Y, Wang Z, Xu Y, Li X, Peng X. Correlation between critical thinking and emotional intelligence of medical undergraduates. China Higher Med Edu. 2017(08):5-6+52.

10. Huang L, Wang Z, Yao Y, Shan C, Wang H, Zhu M, Lu Y, Sun P, Zhao X. Exploring the association between parental rearing styles and medical students' critical thinking disposition in China. BMC Med Educ. 2015;15.

11. Hong S, Yu P. Comparison of the effectiveness of two styles of case-based learning implemented in lectures for developing nursing students' critical thinking ability: A randomized controlled trial. Int J Nurs Stud. 2017;68:16-24.

12. Mayer JD, Caruso DR, Salovey P. The Ability Model of Emotional Intelligence: Principles and Updates. Emot Rev. 2016;8(4):290-300.

13. Ranasinghe $P$, Wathurapatha WS, Mathangasinghe $Y$, Ponnamperuma G. Emotional intelligence, perceived stress and academic performance of Sri Lankan medical undergraduates. BMC Med Educ. 2017;17:41.

14. Ruiz-Ariza A, Suarez-Manzano S, Lopez-Serrano S, Martinez-Lopez EJ. The effect of cooperative highintensity interval training on creativity and emotional intelligence in secondary school: A randomised controlled trial. Eur Phys Educ Rev. 2019;25(2):355-73.

15. Yao XN, Yuan SG, Yang WJ, Chen QL, Wei DT, Hou YL, Zhang LJ, Qiu J, Yang D. Emotional intelligence moderates the relationship between regional gray matter volume in the bilateral temporal pole and critical thinking disposition. Brain Imaging Behav. 2018;12(2):488-98.

16. Benzo RP, Kirsch JL, Dulohery MM, Abascal-Bolado B. Emotional Intelligence: A Novel Outcome Associated with Wellbeing and Self-Management in Chronic Obstructive Pulmonary Disease. Ann Am Thoracic Society. 2016;13(1):10-6.

17. Cejudo J, Rodrigo-Ruiz D, Luz Lopez-Delgado M, Losada L. Emotional Intelligence and Its Relationship with Levels of Social Anxiety and Stress in Adolescents. Int J Environ Res Public Health. 2018;15(6).

18. Borges NJ, Thompson BM, Roman BJ, Townsend MH, Carchedi LR, Cluver JS, Frank JB, Haidet PM, Levine RE. Team Emotional Intelligence, Team Interactions, and Gender in Medical Students During a Psychiatry Clerkship. Acad Psychiatry. 2015;39(6):661-3.

19. van der Linden D, Pekaar KA, Bakker AB, Schermer JA, Vernon PA, Dunkel CS, Petrides KV. Overlap Between the General Factor of Personality and Emotional Intelligence: A Meta-Analysis. Psychol Bull. 2017;143(1):36-52. 
20. Coetzee M, Harry N. Emotional intelligence as a predictor of employees' career adaptability. J Vocat Behav. 2014;84(1):90.

21. Gribble N, Ladyshewsky RK, Parsons R. The impact of clinical placements on the emotional intelligence of occupational therapy, physiotherapy, speech pathology, and business students: a longitudinal study. BMC Med Educ. 2019;19:90.

22. Kaya H, Senyuva E, Bodur G. Developing critical thinking disposition and emotional intelligence of nursing students: a longitudinal research. Nurse Educ Today. 2017;48:72-7.

23. Kaya $H$, Senyuva E, Bodur $G$. The relationship between critical thinking and emotional intelligence in nursing students: A longitudinal study. Nurse Educ Today. 2018;68:26-32.

24. Pines EW, Rauschhuber ML, Cook JD, Norgan GH, Canchola L, Richardson C, Jones ME. Enhancing Resilience, Empowerment, and Conflict Management Among Baccalaureate Students Outcomes of a Pilot Study. Nurse Educ. 2014;39(2):85-90.

25. Broukhim M, Yuen F, McDermott H, Miller K, Merrill L, Kennedy R, Wilkes M. Interprofessional conflict and conflict management in an educational setting. Med Teach. 2019;41(4):408-16.

26. Grubaugh ML, Flynn L. Relationships Among Nurse Manager Leadership Skills, Conflict Management, and Unit Teamwork. J Nurs Adm. 2018;48(7-8):383-8.

27. Kim W, Nicotera AM, McNulty J. Nurses' perceptions of conflict as constructive or destructive. J Adv Nurs. 2015;71(9):2073-83.

28. Thomson K, Outram S, Gilligan C, Levett-Jones T. Interprofessional experiences of recent healthcare graduates: A social psychology perspective on the barriers to effective communication, teamwork, and patient-centred care. J Interprof Care. 2015;29(6):634-40.

29. Greer LL, Saygi O, Aaldering H, de Dreu CKW. Conflict in medical teams: opportunity or danger? Med Educ. 2012;46(10):935-42.

30. Browne AM, Deutsch ES, Corwin K, Davis DH, Teets JM, Apkon M. An IDEA: Safety Training to Improve Critical Thinking by Individuals and Teams. Am J Med Qual. 2019; doi:10.1177/1062860618820687.

31. Raosoft. Sample Size Calculation. 2004. http://www.raosoft.com/samplesize.html. Accessed 01 Jul 2016.

32. Peng M, Wang G, Chen J, Chen M, Bai H, Li S, Li J, Cai Y, Wang J, Yin L. Validity and reliability of the chinese critical thinking disposition inventory. J Chin J Nurs. 2004;39(9):644-7.

33. Facione NC, Facione PA, Sanchez CA. Critical thinking disposition as a measure of competent clinical judgment: the development of the California Critical Thinking Disposition Inventory. J Nurs Educ. 1994;33(8):345-50.

34. Wang C, He Z. The Relationship between Parental Rearing Styles with General Self- efficacy and Emotional Intelligence in Middle School students. Chin Ment Health J. 2002(11):781-2+5.

35. Zhang Y, Long LR, Gong TL, Ma YF. A Study on the Validity and Reliability of Rahim Organizational Conflict Inventory-II in China Background. Manage Rev. 2012(01):108-15.

36. Huang L, Wang Z, Yao Y, Shan C, Wang H, Zhu M, Lu Y, Sun P, Zhao X. Exploring the association between parental rearing styles and medical students' critical thinking disposition in China. BMC Med Educ. 2015;15:88.

37. Raymond C, Profetto-McGrath J, Myrick F, Strean WB. Nurse educators' critical thinking: A mixed methods exploration. Nurse Educ Today. 2018;66:117-22.

Page $11 / 14$ 
38. Czabanowska K, Malho A, Schröder-Bäck P, Popa D, Burazeri G. Do we develop public health leaders?association between public health competencies and emotional intelligence: a cross-sectional study. BMC Med Educ. 2014;14:83.

39. Augusto Landa JM, Lopez-Zafra E, Berrios Martos MP, del Carmen Aguilar-Luzon M. The relationship between emotional intelligence, occupational stress and health in nurses: A questionnaire survey. Int $\mathrm{J}$ Nurs Stud. 2008;45(6):888-901.

40. Chan JCY, Sit ENM, Lau WM. Conflict management styles, emotional intelligence and implicit theories of personality of nursing students: A cross-sectional study. Nurse Educ Today. 2014;34(6):934-9.

41. Shaw JD, Zhu J, Duffy MK, Scott KL, Shih HA, Susanto E. A Contingency Model of Conflict and Team Effectiveness. J Appl Psychol. 2011;96(2):391-400.

42. Broadbent J, Poon WL. Self-regulated learning strategies \& academic achievement in online higher education learning environments: A systematic review. Internet High Educ. 2015;27:1-13.

\section{Tables}

Table 1 Sample characteristics $(n=269)$

\begin{tabular}{|c|c|c|}
\hline & N (\%) \\
\hline Gender & Male & $\begin{array}{lll}88 & \square 32.7 \square \\
\end{array}$ \\
\hline \multirow[t]{3}{*}{ Grade } & Second year & $94 \quad \square 34.9 \square$ \\
\hline & Third year & $84 \quad \square 31.2 \square$ \\
\hline & Fourth year & $91 \quad \square 33.9 \square$ \\
\hline \multirow[t]{2}{*}{ Major } & Nursing & $72 \square 26.8 \square$ \\
\hline & $\begin{array}{l}\text { Clinical medicine } \\
\text { Pharmacy } \\
\text { Oral hygiene } \\
\text { Preventive medicine } \\
\text { Else } \\
\leq 70\end{array}$ & $\begin{array}{lc}71 & \square 26.4 \square \\
39 & \square 14.5 \square \\
28 & \square 10.4 \square \\
26 & \square 9.7 \square \\
33 & \square 12.2 \square \\
23 & (8.6)\end{array}$ \\
\hline Grade point average & $\begin{array}{l}71-80 \\
\geq 81\end{array}$ & $\begin{array}{l}125 \\
121\end{array}$ \\
\hline Reading habit & $\begin{array}{l}\text { Yes } \\
\text { No }\end{array}$ & $\begin{array}{ll}202 & (75.1) \\
67 & (24.9)\end{array}$ \\
\hline Part-time experience & $\begin{array}{l}\text { Yes } \\
\text { No }\end{array}$ & $\begin{array}{l}172(63.9) \\
97 \quad(36.1)\end{array}$ \\
\hline Internship experience & $\begin{array}{l}\text { Yes } \\
\text { No }\end{array}$ & $\begin{array}{ll}193 & (71.7) \\
76 & (28.3)\end{array}$ \\
\hline
\end{tabular}

Table 2 Descriptive analysis of CTDI-CV $\square=269 \square$ 


\begin{tabular}{|c|c|c|c|c|c|c|c|c|}
\hline \multirow[t]{2}{*}{ Dimensions } & \multicolumn{2}{|l|}{$<40$} & \multicolumn{2}{|c|}{$40-49$} & \multicolumn{2}{|c|}{$\geq 50$} & \multirow[t]{2}{*}{ Mean } & \multirow[t]{2}{*}{$\mathrm{SD}$} \\
\hline & $\mathrm{n}$ & ८\%० & $\mathrm{n}$ & ८\%॰ & $\mathrm{n}$ & ए\%० & & \\
\hline Truth-seeking & 185 & 68.77 & 79 & 29.37 & 5 & 1.86 & 36.67 & 6.00 \\
\hline Open-mindedness & 110 & 40.89 & 145 & 53.91 & 14 & 5.20 & 40.64 & 5.56 \\
\hline Analyticity & 76 & 28.25 & 167 & 62.08 & 26 & 9.67 & 42.48 & 5.32 \\
\hline Systematicity & 157 & 58.36 & 105 & 39.04 & 7 & 2.60 & 38.39 & 5.77 \\
\hline Self-confidence & 133 & 58.74 & 124 & 36.80 & 12 & 4.46 & 38.98 & 5.85 \\
\hline Inquisitiveness & 84 & 31.23 & 153 & 56.87 & 32 & 11.90 & 42.94 & 5.85 \\
\hline Cognitive maturity & 97 & 36.06 & 142 & 52.79 & 30 & 11.15 & 41.02 & 7.50 \\
\hline
\end{tabular}

Table 3 Means and standard deviations of the EI for males and females $\llbracket n=269$ 口

\begin{tabular}{|c|c|c|c|c|c|c|c|c|c|c|}
\hline \multirow{2}{*}{$\begin{array}{l}\text { Dimensions } \\
\text { Gender }^{\mathrm{a}} \\
\end{array}$} & \multicolumn{2}{|c|}{$\begin{array}{l}\text { Perceived } \\
\text { emotion }\end{array}$} & \multicolumn{2}{|c|}{$\begin{array}{l}\text { Self- } \\
\text { emotional } \\
\text { regulation }\end{array}$} & \multicolumn{2}{|c|}{$\begin{array}{l}\text { Regulation } \\
\text { of others } \\
\text { emotions }\end{array}$} & \multicolumn{2}{|c|}{$\begin{array}{l}\text { Use of } \\
\text { emotions }\end{array}$} & \multicolumn{2}{|c|}{ EI score } \\
\hline & $\mathrm{M}$ & F & $\mathrm{M}$ & $\mathrm{F}$ & $\mathrm{M}$ & $F$ & $\mathrm{M}$ & F & $\mathrm{M}$ & F \\
\hline Mean & 3.49 & 3.66 & 3.68 & 3.89 & 3.56 & 3.76 & 3.72 & 3.96 & 118.47 & 125.18 \\
\hline SD & 0.58 & 0.48 & 0.60 & 0.48 & 0.59 & 0.50 & 0.73 & 0.63 & 17.05 & 13.60 \\
\hline $\mathrm{t}$ & \multicolumn{2}{|c|}{$-2.479^{*}$} & \multicolumn{2}{|c|}{$-3.096^{*}$} & \multicolumn{2}{|c|}{$-3.015^{*}$} & \multicolumn{2}{|c|}{$-2.790^{*}$} & \multicolumn{2}{|l|}{$-3.487^{*}$} \\
\hline
\end{tabular}

${ }^{\text {a }} \mathrm{M}=$ Male, $\mathrm{F}=$ Female.

$* \mathrm{p}<0.05$.

Table 4 Means and standard deviations of the five conflict management styles $\llbracket \mathrm{n}=269$ [

\begin{tabular}{llllll}
\hline Dimensions & Integration & Compromise & Domination & Avoidance & Compliance \\
\hline Mean & 3.90 & 3.72 & 2.81 & 3.56 & 2.99 \\
SD & 0.54 & 0.57 & 0.75 & 0.65 & 0.66 \\
\hline
\end{tabular}

Table 5 Correlation between $\mathrm{CT}$ and EI , CMM $\square$ r value $\square$

\begin{tabular}{lllllllll}
\hline Dimensions & $\mathrm{T}$ & $\mathrm{O}$ & $\mathrm{A}$ & $\mathrm{S}$ & $\mathrm{SC}$ & $\mathrm{I}$ & $\mathrm{C}$ & $\mathrm{CT}$ \\
\hline Perceived emotion & $0.155^{*}$ & $0.207^{* *}$ & $0.276^{* *}$ & $0.353^{* *}$ & $0.207^{* *}$ & $0.378^{* *}$ & $0.293^{* *}$ & $0.409^{* *}$ \\
Self-emotional regulation & $0.267^{* *}$ & $0.332^{* *}$ & $0.312^{* *}$ & $0.347^{* *}$ & $0.213^{* *}$ & $0.339^{* *}$ & $0.217^{* *}$ & $0.437^{* *}$ \\
Regulation of others emotions & $0.161^{* *}$ & $0.252^{* *}$ & $0.319^{* *}$ & $0.227^{* *}$ & $0.206^{* *}$ & $0.334^{* *}$ & $0.174^{* *}$ & $0.359^{* *}$ \\
Use of emotions & 0.116 & $0.201^{* *}$ & $0.164^{* *}$ & $0.204^{* *}$ & $0.122^{*}$ & $0.288^{* *}$ & $0.225^{* *}$ & $0.290^{* *}$ \\
EI score & $0.223^{* *}$ & $0.308^{* *}$ & $0.334^{* *}$ & $0.345^{* *}$ & $0.207^{* *}$ & $0.399^{* *}$ & $0.289^{* *}$ & $0.457^{* *}$ \\
Integration & $0.349^{* *}$ & $0.441^{* *}$ & $0.260^{* *}$ & $0.346^{* *}$ & 0.050 & $0.372^{* *}$ & $0.328^{* *}$ & $0.469^{* *}$ \\
Compromise & 0.114 & $0.267^{* *}$ & $0.160^{* *}$ & $0.204^{* *}$ & 0.051 & $0.241^{* *}$ & $0.131^{*}$ & $0.251^{* *}$ \\
Domination & 0.116 & $-0.144^{*}$ & -0.119 & $-0.123^{*}$ & 0.007 & $-0.121^{*}$ & $-0.132^{* *}$ & $-0.164^{* *}$ \\
Avoidance & -0.015 & 0.067 & $0.153^{*}$ & 0.020 & -0.070 & 0.060 & 0.041 & 0.053 \\
Compliance & $-0.224^{* *}$ & -0.082 & $-0.125^{*}$ & $-0.246^{* *}$ & -0.101 & -0.054 & -0.062 & $-0.192^{* *}$ \\
\hline
\end{tabular}


$* \mathrm{p}<0.05 ; * * \mathrm{p}<0.01$

T Truth-seeking, O Open-mindedness, A Analyticity, S Systematicity, SC Self-confidence, I Inquisitiveness, C Cognitive maturity, CT Critical thinking

Table 6 Multivariable linear regression analysis between CT and EI, CMM

\begin{tabular}{lcccccc}
\hline Variables & $\mathrm{SE}$ & $\mathrm{B}$ & $\beta$ & $\mathrm{R}^{2}$ & $\triangle \mathrm{R}^{2}$ & $\mathrm{t}$ \\
\hline Constant & 13.951 & 190.235 & - & - & - & $13.636^{* *}$ \\
Integration & 3.058 & 16.133 & 0.319 & 0.220 & 0.217 & $5.276^{* *}$ \\
Perceived emotion & 0.351 & 1.050 & 0.199 & 0.280 & 0.058 & $3.340^{* *}$ \\
Compliance & 2.047 & -9.036 & -0.218 & 0.331 & 0.049 & $-4.415^{* *}$ \\
Domination & 1.820 & -5.004 & -0.138 & 0.350 & 0.019 & $-2.749^{*}$ \\
Self-emotional regulation & 0.373 & 0.905 & 0.159 & 0.364 & 0.012 & $2.424^{*}$ \\
\hline
\end{tabular}

$* \mathrm{p}<0.05 ; * * \mathrm{p}<0.01$ 